\title{
Correction to: Arctic Micromonas uses protein pools and non- photochemical quenching to cope with temperature restrictions on Photosystem II protein turnover
} Guangyan $\mathrm{Ni}^{1,2} \cdot$ Gabrielle Zimbalatti $^{1} \cdot$ Cole D. Murphy $^{1} \cdot$ Audrey B. Barnett $^{3} \cdot$ Christopher M. Arsenault $^{1}$.
Gang $\mathrm{Li}^{1,4} \cdot$ Amanda M. Cockshutt $^{1} \cdot$ Douglas A. Campbell

Published online: 18 December 2017

๑) Springer Science+Business Media B.V., part of Springer Nature 2017

Correction to: Photosynth Res (2017) 131:203-220

https://doi.org/10.1007/s11120-016-0310-6

In Table 2 of the original publication, all instances of $\mathrm{k}_{\text {rec }}$

in the Parameter and Equation columns should read $\mathrm{k}_{\text {recinact. }}$.

The original article can be found online at https://doi.

org/10.1007/s11120-016-0310-6.

Douglas A. Campbell

dcampbell@mta.ca

1 Department of Chemistry \& Biochemistry, Mount Allison University, 63B York St., Sackville, NB E4L3M7, Canada

2 Key Laboratory of Vegetation Restoration and Management of Degraded Ecosystems, South China Botanical Garden, CAS, Guangzhou 510160, China

3 Michigan Technological University, Houghton, MI 49931, USA

4 Key Laboratory of Tropical Marine Bio-resources and Ecology, South China Sea Institute of Oceanology, CAS, Guangzhou 510301, China 